\title{
Transient Performance Enhancement of PMSG-Based Wind Turbine Using Superconducting Fault Current Limiter
}

\author{
Lei Chen ${ }^{1, *}$, Xin Sui ${ }^{2}$, Huiwen $\mathrm{He}^{3}$, Yu Lei ${ }^{1}$, and Fei Tang ${ }^{1}$ \\ ${ }^{1}$ School of Electrical Engineering, Wuhan University, 430072 Wuhan, China \\ ${ }^{2}$ China Yangtze Power Co., Ltd., 443002 Yichang, China \\ ${ }^{3}$ China Electric Power Research Institute, 430074 Wuhan, China
}

\begin{abstract}
Recently, a major part of the newly installed wind turbines are of the variable-speed type using permanent-magnet synchronous generators (PMSGs), which are required to meet grid interconnection codes for fault ride-through (FRT), so as to actively contribute to system stability during a wide range of network fault scenarios. This paper suggests a resistive type superconducting fault current limiter (SFCL) to enhance the FRT capability of a PMSG-based wind turbine. The SFCL's mathematical model is presented in brief, and in terms of the PMSG's theoretical model, the SFCL's influence mechanism to its FRT capability is discussed. Furthermore, the detailed model of a typical PMSG-based wind turbine with the SFCL is built in MATLAB/SIMULINK, and transient simulations are done to assess the SFCL's performance behaviours. From the demonstrated results, the SFCL can availably limit the fault current and maintain a stable DC-link voltage. And also, the SFCL is able to smooth the power fluctuation and strengthen the wind power system's transient performance.
\end{abstract}

\section{Introduction}

The growing concern of green-house gases and the depleted resources of fossil fuels have stimulated the utilization of renewable energy sources [1]. Wind energy, of all these options, is the most prominent alternative energy source for producing electric power and solving energy shortage due to its zero fuel cost, no carbon emission, cleanliness and renewable nature [2]-[5]. Among the generator types used for wind turbines, the technical development has moved from fixed-speed to variable-speed concepts. That is to say, modern wind turbine generation systems are usually the variable-speed type using either doubly fed induction generators (DFIGs) or permanent-magnet synchronous generators (PMSGs).

Actually, all of the wind turbine technologies, irrespective of generator type, applied in high-power wind turbines, are required to meet grid interconnection codes for fault ride-through (FRT), so as to actively contribute to system stability during a wide range of network fault scenarios. In regards to PMSG, it has many advantages such as the self-excitation capability, leading to a high power factor and high efficiency operation, and the study of its transient characteristics and FRT issues is valuable.

In terms of the basic structure of a PMSG-based wind turbine, the generator is connected to the electric power grid through a full-scale back-to-back pulse width modulated (PWM) converter. When a short-circuit fault happens, the dc-link voltage cannot be controlled by the line-side converter (LSC), and it is increased excessively since the wind turbine continues to generate the power but the grid cannot absorb the generated power fully. As a result, the key points of achieving the FRT operation are to ensure the power balance and maintain a stable DC-link voltage. In [6], [7], it is proposed that the dc link voltage can be controlled by the generator side converter (GSC) instead of the LSC, and the dc link voltage may be adjusted to remain unchanged by increasing the generator speed. But, the amount of energy stored in the turbine inertia is not so large, especially in the case of that the generator operates near the rated speed before grid faults, and the response abilities of the controllers should be optimized further. In [8], [9], some improved control methods are applied to strengthen the FRT capability of a PMSG, and in [10], the energy storage systems (ESS) and braking choppers are introduced. During grid faults, the dc-link voltage is controlled by the ESS instead of the LSC, whereas the LSC is exploited as a STATCOM to inject reactive current into the grid for assisting in the grid voltage recovery.

From the viewpoint of improving the PMSG's FRT capability more actively, it may be suggested to employ an efficient superconducting fault current limiter (SFCL), which has some unique advantages in solving technical problems. The suggested auxiliary equipment can help to consume the surplus power and compensate the voltage sags, as a result in suppressing the DC-link voltage oscillation and ensuring the stable operation of the PMSG.

In this paper, according to a resistive type superconducting fault current limiter, its application in enhancing the FRT capability of a typical PMSG-based wind turbine is investigated in detail.

\section{Theoretical analysis}

\subsection{Mathematical Modelling of the Resistive Type SFCL}

Based on the experimental studies for a resistive SFCL [11], its mathematical model can be expressed as:

$$
R(t)= \begin{cases}0 & \left(t<t_{0}\right) \\ R_{n}\left[1-\exp \left(-\frac{t-t_{0}}{\tau}\right)\right]^{1 / 2} & \left(t_{0} \leq t<t_{1}\right) \\ a_{1}\left(t-t_{1}\right)+b_{1} & \left(t_{1} \leq t<t_{2}\right) \\ a_{2}\left(t-t_{2}\right)+b_{2} & \left(t_{2} \leq t<t_{3}\right)\end{cases}
$$

Where $R_{\mathrm{n}}, \tau$ represent the impedance being saturated at normal temperature and time constant, respectively. In addition, $t_{1}, t_{2}$, and $t_{3}$ represent quench-starting time, the first recovery-starting time, and the secondary recovery- 
starting time, respectively. $a_{1}, a_{2}, b_{1}$, and $b_{2}$ are coefficients of the first-order linear function. Fig. 1 shows the detailed quenching and recovery characteristics of the suggested resistive SFCL.

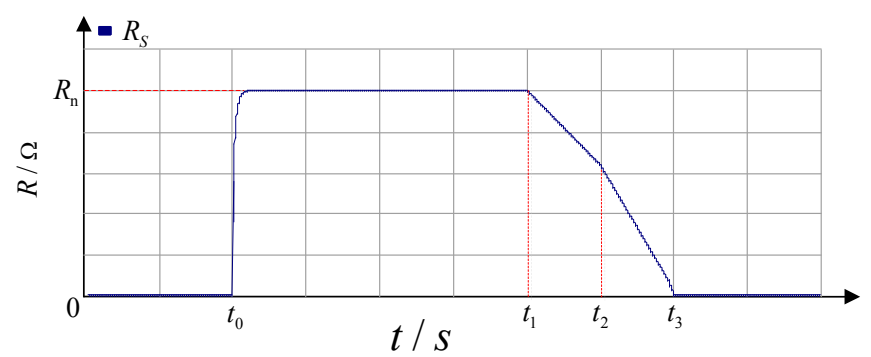

Figure 1. Quenching and recovery characteristics of the resistive type SFCL.

\subsection{Influence Mechanism of the Suggested SFCL to the FRT Improvement of PMSG}

Fig. 2 shows the schematic diagram of a PMSG wind turbine system with the SFCL. Traditionally, the GSC is used to realize the maximum power point tracking (MPPT) control, whereas the LSC controls the DC-link voltage $V_{\mathrm{DC}}$ as well as the reactive power to the electric power grid. The suggested SFCL is installed at the point of common coupling (PCC) between the LSC and the main grid.

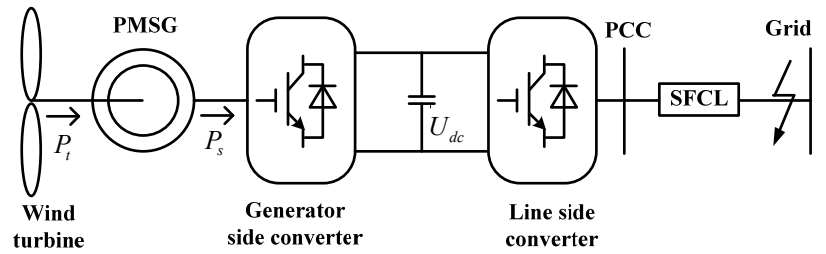

Figure 2. Configuration of a PMSG wind turbine system with the SFCL.

The DC-link capacitor is used to deliver the incoming power from the generator side to the grid side, and in the case of neglecting the converter loss, the generator power and the DC-link capacitor power can be expressed as:

$$
\begin{gathered}
P_{\text {gen }}=P_{t}-J_{e q} \frac{d \omega_{m}}{d t}-P_{g-\text { loss }} \\
P_{c a p}=C \frac{d V_{d c}}{d t} V_{d c} P_{t}=P_{\text {gen }}-P_{\text {grid }}
\end{gathered}
$$

Where $P_{\text {gen }}$ is the generator power; $P_{\text {grid }}$ is the grid-side power; $P_{g \text {-loss }}$ is the generator loss; $V_{\mathrm{dc}}$ is the dc-link voltage; $C$ is the dc-link capacitor; $P_{\text {cap }}$ is the dc-link capacitor power.

During the process of a short-circuit fault, the grid voltage drops dramatically. Since the GSC is not directly coupled to the power grid, it continues to operate undisturbed the power flow from the PMSG terminals to the LSC. Meanwhile, the LSC is automatically affected by being coupled to the main grid. Its control of the DClink voltage is quickly limited and it is therefore not anymore able to deliver the whole active power to the power grid. If the power surplus cannot be timely and effectively dissipated, it will start to charge the DC-link capacitor and cause the overvoltage in the DC-link. Furthermore, this imbalanced power can cause the DC- link voltage oscillations, increase the damaging risk of the converter, and affect the steady operation of the PMSG-based wind generation system.

When the resistive type SFCL is applied, its major contributions are to consume the surplus power, suppress the grid-side current, and compensate the voltage sags. According to the equivalent circuit for power transmission analysis shown in Fig. 3, the positive effects of introducing the current-limiting resistance on the power balance are derived. Notice that since the PMSG generator is connected to the grid through a full-scale converter, only the active power of the generator is transferred to the grid.
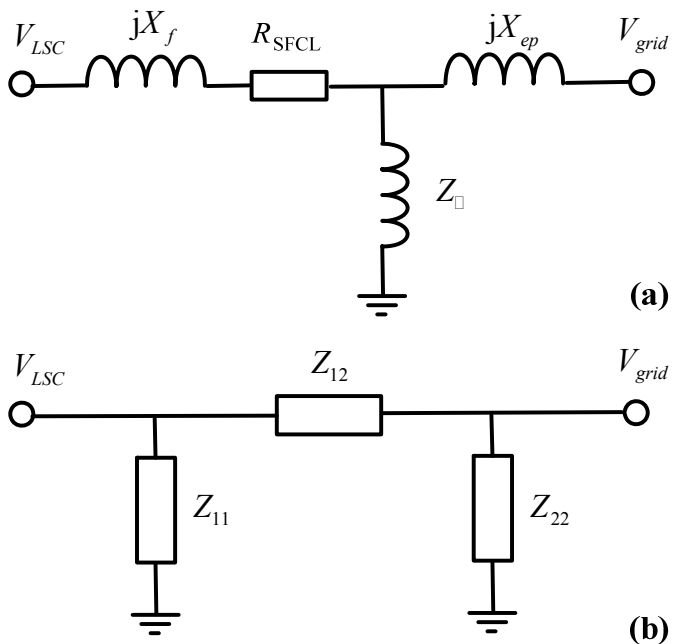

Figure 3. Equivalent circuit used for power transmission analysis. (a) delta connection, and (b) star connection.

As the reactive power of the generator cannot be exchanged through the DC-link in the converter system, the grid-side converter, whose electric frequency and voltage are fixed to the grid, is set to control the reactive power/voltage on the grid.

The grid power under the normal condition is:

$$
P_{\text {grid }-n}=\frac{V_{L S C} V_{\text {grid }} \sin \delta}{X_{f}+X_{e q}}
$$

where $V_{L S C}$ is the fundamental voltage of the LSC; $\delta$ is the angle between the converter bus voltage and grid voltage; $X_{f}$ is the reactance of the reactor used as a filter between the LSC and the power grid.

After the fault, the current-limiting resistance $R_{\mathrm{SFCL}}$ will be inserted into the main circuit, and the transfer impedances $Z_{11}, Z_{12}$ and $Z_{22}$ can be expressed as:

$$
\left\{\begin{aligned}
Z_{11} & =R_{S F C L}+\mathrm{j} X_{f}+Z_{\square} / / \mathrm{j} X_{e q} \\
Z_{22} & =\mathrm{j} X_{e q}+Z_{\square} / /\left[R_{S F C L}+\mathrm{j} X_{f}\right] \\
Z_{12} & =R_{S F C L}+\mathrm{j}\left(X_{f}+X_{e q}\right) \\
& +\frac{\left[R_{S F C L}+\mathrm{j} X_{f}\right] \mathrm{j} X_{e q}}{Z_{\square}}
\end{aligned}\right.
$$

Where $Z_{\square}$ is the additional impedance which will depend on the fault type. In terms of the three-phase ground fault, $Z_{\square}$ will be equal to zero, and it can be obtained that $Z_{11}=R_{S F C L}+\mathrm{j} X_{f}=\left|Z_{11}\right| \angle \phi_{11}, Z_{22}=\mathrm{j} X_{e q}=X_{e q} \angle 90^{\circ}$, 
and $Z_{12}=\left|Z_{12}\right| \angle \phi_{12}=\infty$. As a result, the grid power under the fault can be expressed as:

$$
\begin{aligned}
P_{\text {grid }-f} & =\frac{V_{L S C}^{2}}{\left|Z_{11}\right|} \sin \left(90^{\circ}-\phi_{11}\right)+\frac{V_{L S C} V_{\text {grid }}}{\left|Z_{12}\right|} \sin \left(\delta-90^{\circ}+\phi_{12}\right) \\
& =\frac{V_{L S C}^{2}}{\left|Z_{11}\right|} \sin \left(90^{\circ}-\phi_{11}\right)
\end{aligned}
$$

According to (6), when the resistive type SFCL is applied, this suggested device can effectively dissipate the surplus power and improve the wind generation system's transient performance. Applying the SFCL can also limit the fault current from the LSC to the grid-side. Since this fault current will be constrained by the converter's maximum transfer capability, its first peak will commonly not rise to a too high level, and during the design of the current-limiting ratio, the setting of $R_{S F C L}$ should be carefully weighed.

\section{Simulation analyses}

To quantitatively evaluate the SFCL's effects on the FRT capability of a PMSG based wind turbine, the simulation model corresponding to Fig. 2 is built in MATLAB/SIMULINK, and parts of the simulation parameters are indicated as Table I.

In this paper, an improved control strategy is adopted for the PMSG based wind turbine [12]. The d-axis current reference of the GSC is set to zero, and the q-axis controller is still used to regulate the dc-link voltage. Regarding the LSC which is used to control the generator power, a dynamic amplitude limit is newly introduced to suppress the $\mathrm{d}$-axis current reference under fault conditions, as a result of that the PMSG power can be properly adjusted. Furthermore, the LSC's q-axis control loop can inject the reactive current according to the power support requirements.

Note that, the method of using pitch angle control (PAC) is also applied, the comparison of the resistive type SFCL and the PAC for improving the PMSG's transient performance is done.

Table 1. Main Simulation Parameters of the System Model.

\begin{tabular}{|c|c|}
\hline \multicolumn{2}{|c|}{ Resistive Type SFCL } \\
\hline Superconducting coil $R_{\mathrm{SFCL}}$ & $5 \Omega$ \\
\hline \multicolumn{2}{|c|}{ Main Grid } \\
\hline Rated Voltage/frequency & $690 \mathrm{~V} / 50 \mathrm{~Hz}$ \\
\hline Filter inductance & $0.395 \mathrm{mH}$ \\
\hline \multicolumn{2}{|c|}{ PMSG-based Wind Turbine } \\
\hline Rated capacity/voltage & $1.5 \mathrm{MW} / 690 \mathrm{~V}$ \\
\hline Stator resistance/inductance & $3.17 \mathrm{~m} \Omega / 3.21 \mathrm{mH}$ \\
\hline Dc-link voltage & $1200 \mathrm{~V}$ \\
\hline Dc-link capacitance & $0.023 \mathrm{~F}$ \\
\hline
\end{tabular}

The simulation conditions are set as that, a threephase grounded fault happens at $t=5 \mathrm{~s}$, and the fault duration/resistance is set as $0.5 \mathrm{~s} / 0.1 \Omega$. Figs $4-6$ show the
PMSG's operating characteristics when the SFCL and PAC are respectively adopted.

Besides, the PMSG's performance characteristics under the double-phase grounded fault are simulated, and the detailed waveforms are show in Figs. 7-9. From the demonstrated results, applying the SFCL can help to limit the fault current and maintain a stable DC-link voltage. And also, the SFCL is able to smooth the power fluctuation and strengthen the wind power system's operational stability. Compared to the method of using the PAC, introducing the suggested SFCL can play a better role in enhancing the wind power system's transient performance.

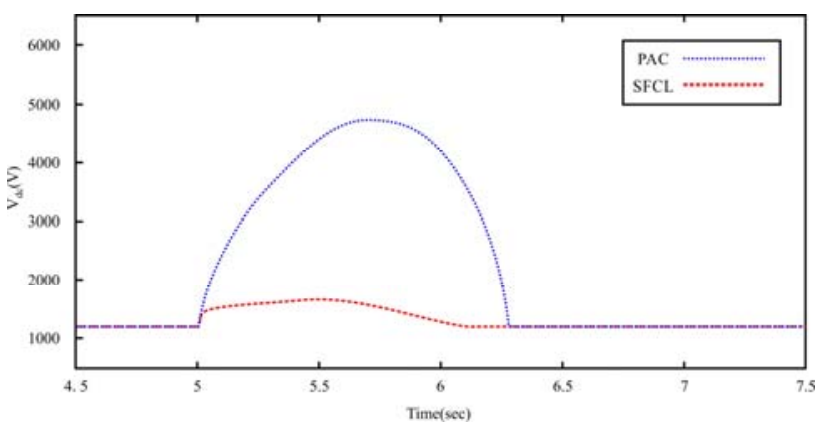

Figure 4. Dc-link voltage of the converter used in the PMSG under the three-phase grounded fault.

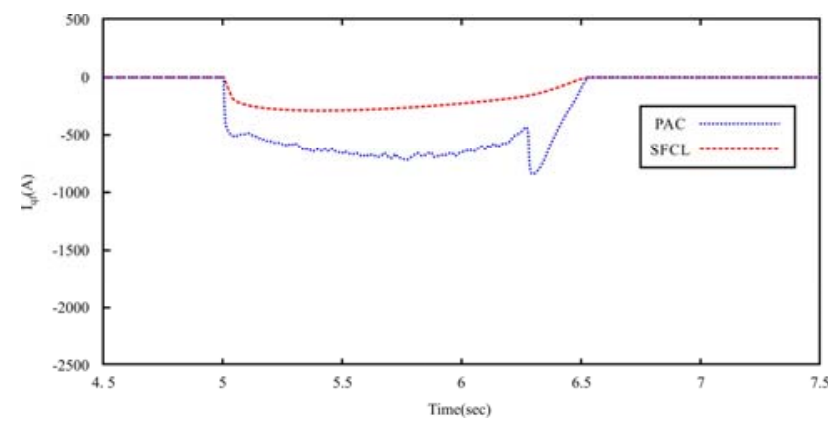

Figure 5. Injected reactive current to the grid under the threephase grounded fault.

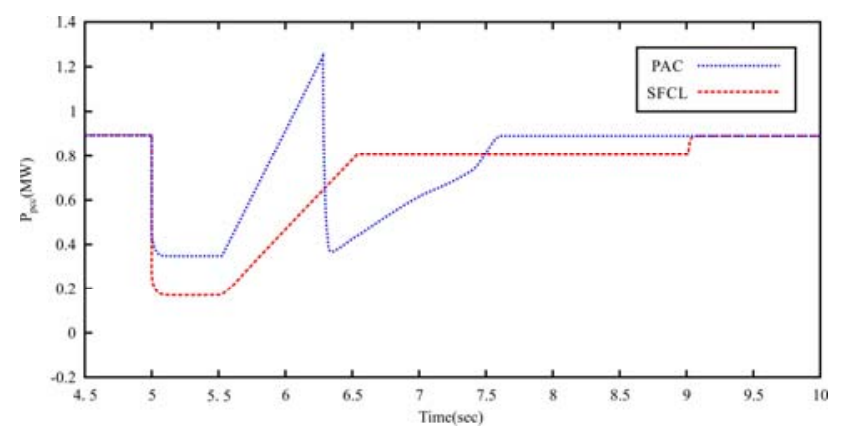

Figure 6. Incoming active power to the PCC under the threephase grounded fault. 


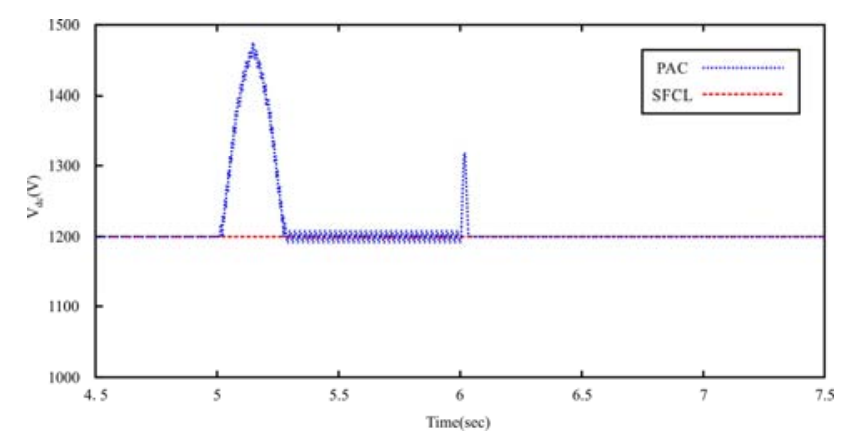

Figure 7. Dc-link voltage of the converter used in the PMSG under the double-phase grounded fault.

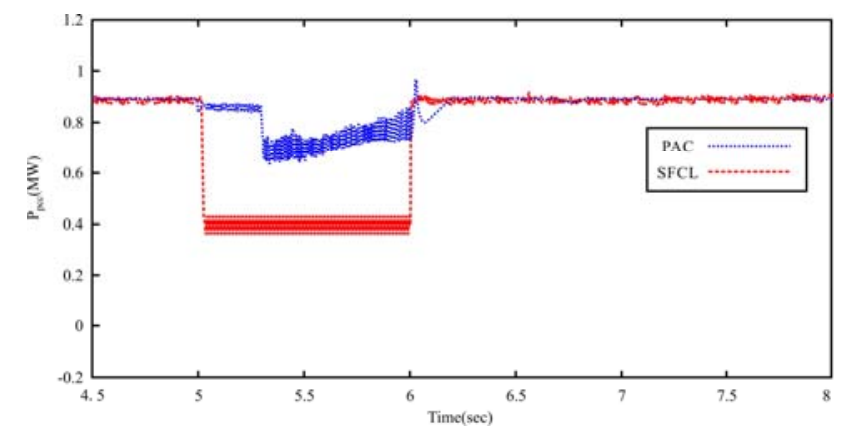

Figure 8. Incoming active power to the PCC in under the double-phase grounded fault.

\section{Conclusion}

In this paper, a resistive type superconducting fault current limiter is suggested to enhance the FRT capability of a PMSG-based wind turbine. Theoretical derivation and simulation analysis are both performed, and the comparison of the SFCL and the PAC for improving the PMSG's transient performance is done. From the demonstrated results, the SFCL can availably limit the fault current and maintain a stable DC-link voltage. And also, the SFCL is able to smooth the power fluctuation and strengthen the wind power system's operational stability to a certain extent.

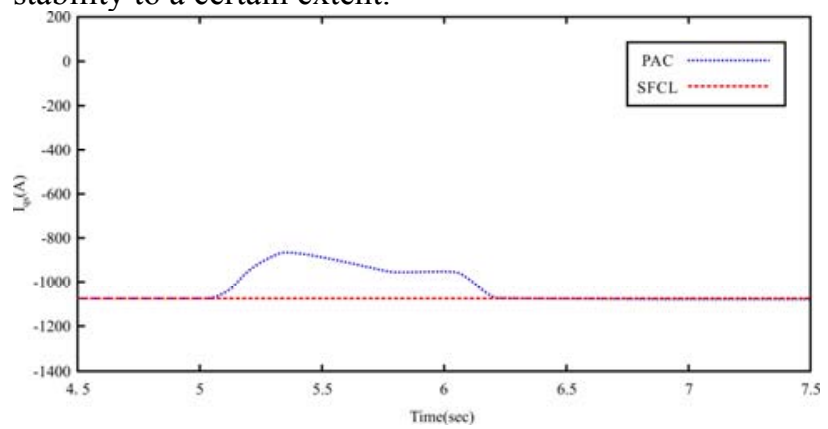

Figure 9. Generated active current by generator under the double-phase grounded fault.

Admittedly, concerning the proposed technical idea which is used to enhance the PMSG's transient performance, a number of aspects should be enriched, such as the optimization design and loss calculation of the SFCL. Moreover, for a wind farm which may be consisting of hundreds of wind turbines, the suggested
SFCL should be installed for the whole wind farm instead of individual wind turbines. These research tasks will be carried out in the near future.

\section{Acknowledgements}

This work was supported in part by the Fundamental Research Funds for the Central Universities (2042014kf0011), and Natural Science Foundation of Hubei Province of China (2014CFB706).

\section{References}

[1] M.M.A Mahfouz, M.A.H. El-Sayed, IET Renew. Power Gen. 8, 1 (2014)

[2] A. Garces, M. Molinas, IEEE Trans. Ind. Electron. 59, 184 (2012)

[3] Y. Xia, K.H. Ahmed, B.W. Williams, IEEE Trans. Ind. Electron. 60, 1122 (2013)

[4] G. Rashid, M.H. Ali, IEEE Trans. Energy Convers. 29, 527 (2014)

[5] C. Wessels, N. Hoffmann, M. Molinas, F.W. Fuchs, IEEE Trans. Ind. Electron. 60, 2864 (2013)

[6] A.D. Hansen, G. Michalke, IET Renew. Power Gen. 3, 333 (2009)

[7] X. Yuan, F. Wang, D. Boroyevich, Y. Li, R. Burgos, IEEE Trans. Power Electron. 24, 2178 (2009)

[8] K.-H. Kim, Y.-C. Jeung, D.-C. Lee, H.-G. Kim, IEEE Trans. Power Electron. 27, 2376 (2012)

[9] M. Popat, B. Wu, N.R. Zargari, IEEE Trans. Sustainable Energy 4, 314 (2013)

[10]T.H. Nguyen, D.-C. Lee, IEEE Trans. Ind. Electron. 60, 2842 (2013)

[11]J.-F. Moon, S.-H. Lim, J.-C. Kim, S.-Y. Yun, IEEE Trans. Appl. Superconduct. 21, 2161 (2011)

[12] M. Nasiri, J. Milimonfared, S.H. Fathi, Renew. Sustain. Energy Rev. 47, 399 (2015) 